\title{
Mutations Affecting Pigment Synthesis in Mycobacterium aurum
}

\author{
By VÉRONIQUE LEVY-FREBAULT AND HUGO L. DAVID \\ Service de la Tuberculose et des Mycobactéries, Institut Pasteur, 25 rue du Docteur Roux, \\ 75024 Paris Cedex 15, France
}

(Received 12 February 1979; revised 8 May 1979)

Pigmentation mutants of Mycobacterium aurum were isolated after chemical mutagenesis. Examination of the pigments extracted from these mutants indicated that at least 15 carotenoids were formed. $\beta$-Carotene was not detected and the major carotene of $M$. aurum appeared to be leprotene. The possible biosynthetic pathway is discussed on the basis of these results.

\section{INTRODUCTION}

Carotenoid pigments are widely distributed in the mycobacteria, and the ability of some species to form these pigments only after photoinduction has been used in mycobacterial taxonomy (Runyon, 1959). However, the study of the distribution of types of carotenoids throughout the genus has not progressed sufficiently to assess their possible chemotaxonomic value. The mycobacteria most extensively investigated in this respect are Mycobacterium marinum, $M$. kansasii, and $M$. phlei. The first two species form $\alpha$-and $\beta$-carotene on photoinduction (Batra, 1971; David, 1974a); these pigments are the end-products of the biosynthetic pathway (Batra, 1971; Ebina et al., 1962; David, 1974b). Mycobacterium phlei forms xanthophylls which were characterized as D-glucosides of carotenoids (Hertzberg \& Liaaen-Jensen, 1967).

Usually the intermediates of carotenoid synthesis are rapidly converted into the endproducts; mutants that accumulate some of the precursors may be useful for their isolation and characterization. This approach was used successfully by Griffiths \& Stanier (1956) in their study of the pigments of Rhodopseudomonas spheroides. Furthermore, a normally minor end-product may accumulate in an appropriate mutant. This appeared to be the case in a mutant of $M$. phlei that accumulated large amounts of the glucosidic carotenoids referred to above.

We have begun to investigate the carotenoid pigments of $M$. aurum (Tsukamura, 1966). This report describes the method of mutagenesis that proved useful for our purposes and gives a preliminary account of the distribution of the pigments formed by some of the mutants isolated. 


\section{METHODS}

Bacteria and growth conditions. A strain of $M$. aurum from our culture collection was used. The bacteria (designated strain $\mathrm{A}^{+}$) were maintained on Lowenstein-Jensen slants. Bacteria for pigment analysis were grown in 100 or $200 \mathrm{ml}$ nutrient broth (Difco) in 250 or $500 \mathrm{ml}$ Erlenmeyer flasks.

Mutagenesis. $N$-Methyl- $N^{\prime}$-nitro- $N$-nitrosoguanidine (MNNG) is an efficient mutagen in $M$. phlei (Konickova-Radochova \& Malek, 1969), so this compound was selected for mutagenesis of $M$. aurum. The required amount of freshly dissolved MNNG (Sigma) was added to the bacteria. The frequency of occurrence of mutants, related to the MNNG concentration, the time of exposure, and the time allowed to elapse after the removal of MNNG (by centrifugation), was estimated by plating appropriate dilutions of the bacterial suspensions on to Lowenstein-Jensen medium in Petri dishes. The cultures were incubated at $37^{\circ} \mathrm{C}$ for 5 to $8 \mathrm{~d}$. Mutant colonies were screened on the basis of their colour, colonies that differed from the parent strain being cloned for further analysis.

Isolation of carotenoid pigments. The harvested cells, suspended in a minimum volume of water, were extracted several times with chloroform/methanol $(1: 1, \mathrm{v} / \mathrm{v})$. The extracts were dried in vacuo and the coloured residues were dissolved in pure acetone. The cloudy acetone extracts were refrigerated at $4{ }^{\circ} \mathrm{C}$ for several hours and then clarified by centrifugation. The coloured supernatants were dried and redissolved in $90 \%(\mathrm{v} / \mathrm{v})$ methanol. Saponification with $10 \%(\mathrm{w} / \mathrm{v}) \mathrm{KOH}$ in methanol for $2 \mathrm{~h}$ at room temperature did not change the chromatographic properties of the pigments and so this step was omitted in most extractions reported here.

Purification of the pigments. To the methanol extracts an equal volume of petroleum ether (b.p. 40 to $65^{\circ} \mathrm{C}$ ) was added, the mixtures were vigorously stirred with a vortex mixer, and the pigments were then allowed to partition. The epiphasic pigments were separated on chromatographic WN-3 neutral alumina (Sigma) in $15 \times 4 \mathrm{~cm}$ columns. The columns were eluted by the stepwise addition of petroleum ether, and $1,2,5,10$ and $25 \%(\mathrm{v} / \mathrm{v})$ acetone in petroleum ether, or by the stepwise addition of $1,5,10,25$ and $50 \%$ $(\mathrm{v} / \mathrm{v})$ ether in petroleum ether. The eluted pigments were further purified by preparative thin-layer chromatography (t.l.c.) using silica gel $\mathrm{G}$ precoated plates (Merck). Normally, the solvent used was $2 \%$ (v/v) acetone in hexane. The hypophasic pigments (xanthophylls) were separated on t.l.c. plates of silica gel G60; the solvent used most frequently was $10 \%(\mathrm{v} / \mathrm{v})$ methanol in benzene.

Partial characterization of the pigments. The pigments were tentatively identified by comparing their absorption spectra and chromatographic properties with data in the literature (Goodwin, 1954; Davies, 1965). The carotenoid content in the extracts was estimated at $450 \mathrm{~nm}$ (Liaaen-Jensen \& Jensen, 1971).

Inhibition of carotenogenesis. The bacteria were grown in the presence of sub-inhibitory concentrations of nicotine (Koch-Light) and diphenylamine (DPA; Sigma), compounds known to inhibit, respectively, the cyclization of lycopene (Howes \& Batra, 1970) and the biosynthesis of the coloured carotenoids (Turian, 1950). Nicotine was without effect in $M$. aurum, and its use was therefore abandoned. Bacteria grown in media containing $10^{-4} \mathrm{M}$-DPA were colourless. To examine the biogenesis of the carotenoids, the DPAtreated cells were harvested, washed and resuspended in fresh medium. The resuspended bacteria were incubated at $37^{\circ} \mathrm{C}$ in a shaker water bath, and the concentration of carotenoids formed was then estimated in extracts of samples obtained at intervals.

\section{RESULTS}

Mutagenesis. The minimal inhibitory concentration of MNNG was 50 to $100 \mu \mathrm{g} \mathrm{ml}^{-1}$ in nutrient broth. The frequency of occurrence of mutants increased with the concentration; the

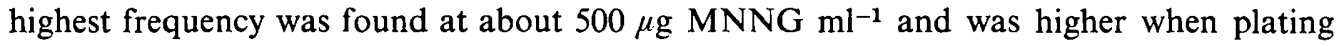
was delayed rather than done immediately (Fig. $1 a$ ). When the bacteria were treated with MNNG at $1 \mathrm{mg} \mathrm{ml}^{-1}$ for $10 \mathrm{~min}$ and platings were done at intervals after the removal of the mutagen, the maximum incidence of mutants was obtained after 4 to $5 \mathrm{~h}$ (Fig. $1 \mathrm{~b}$ ). The frequency of occurrence of mutants was about $10 \%$, indicating that MNNG was a highly efficient mutagen for $M$. aurum.

Bacterial phenotypes. Several surviving colonies differing in colour from the original strain $\mathrm{A}^{+}$were cloned, and their pigments were screened on t.l.c. plates. Three clones were retained. Strain $A_{8}$ was pale yellow, strain $A_{11}$ was colourless and strain $A_{13}$ was ochre. The colourless strain $\left(A_{11}\right)$ was not further examined. Judged from t.l.c. plates, strain $A_{13}$ formed 

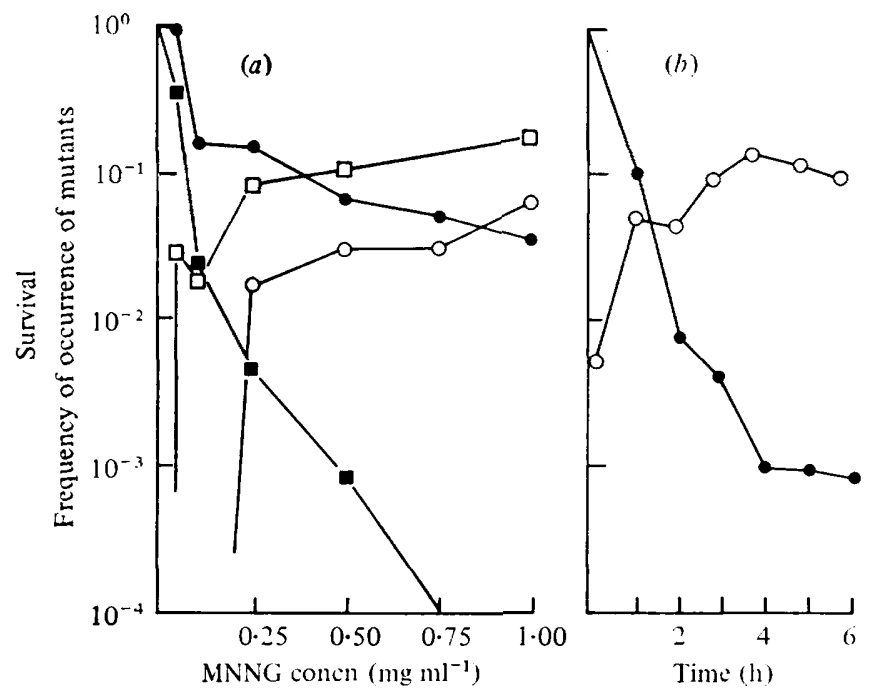

Fig. 1. MNNG-induced mutagenesis in $M$. aurum strain $\mathrm{A}^{+}$. (a) Survival $(\boldsymbol{O}, \mathbf{\square})$ and frequency of occurrence of mutants $(O, \square)$ after 30 min exposure to MNNG. Samples were plated immediately after removal of the mutagen $(\Theta, O)$ and after $4 \mathrm{~h}$ incubation in fresh medium $(\square, \square)$. (b) Time course of survival $(O)$ and frequency of occurrence of mutants $(O)$. After $10 \mathrm{~min}$ exposure to MNNG $\left(1 \mathrm{mg} \mathrm{ml}^{-1}\right)$, bacteria were washed and resuspended in fresh medium and then plated after incubation at $37^{\circ} \mathrm{C}$ for the times indicated.

Table 1. Chromatographic and spectral properties of the carotenoid pigments isolated from $M$. aurum

\begin{tabular}{|c|c|c|c|}
\hline Pigment & $\begin{array}{l}R_{F} \text { in } \\
\text { acetone/ } \\
\text { hexane }\end{array}$ & $\begin{array}{l}\text { Absorption maxima } \\
(\mathrm{nm})\end{array}$ & $\begin{array}{l}\text { Tentative } \\
\text { identification }\end{array}$ \\
\hline I & 0.92 & $415,440,465$ & Neurosporene \\
\hline II & 0.87 & $(425-430), 445,475$ & $\alpha$-Carotene \\
\hline III & 0.84 & $412 \cdot 5,435,440$ & Dihydroxyneurosporene \\
\hline IV & $0 \cdot 83$ & $440,465,(490)$ & Prolycopene-like \\
\hline V & 0.77 & $(435-440), 455,485$ & $\mathrm{NgR}_{13}-2$ \\
\hline VI & 0.77 & $440,465,500$ & Lycopene-like \\
\hline VII & $0 \cdot 71$ & $440,465,495$ & Chlorobactene* \\
\hline VIII & 0.71 & $(430), 447 \cdot 5,475$ & $A_{8}-1$ \\
\hline IX & 0.67 & $445,470,500$ & Lycopene \\
\hline$X$ & 0.66 & $(440), 465,490$ & $\delta$-Carotene \\
\hline XI & $0 \cdot 52$ & $(425-430), 450,475$ & Leprotene \\
\hline XII & $0 \cdot 24$ & $420,440,480$ & $A_{13}-1$ \\
\hline XIII & 0.23 & 435,455 & $\mathrm{NgR}_{13}-4$ \\
\hline XIV & $0 \cdot 19$ & $(425-420), 445,470$ & $A_{8}-2$ \\
\hline XV & 0.03 & $(420-425), 445,467 \cdot 5$ & $A_{8}-3$ \\
\hline
\end{tabular}

the same pigments as strain $\mathrm{A}^{+}$but in much larger amounts. The quantitative analysis of the pigments formed by the two strains showed that the total concentrations of carotenoids were 2.4 and $128.0 \mu \mathrm{g}(100 \mathrm{mg} \text { dry wt bacteria })^{-1}$ for strains $\mathrm{A}^{+}$and $\mathrm{A}_{13}$, respectively.

Strain $A_{13}$ was used for further mutagenesis and from it second-stage mutants $\mathrm{NgR}_{5}$ (brick red), $\mathrm{NgR}_{\mathbf{8}}$ (salmon pink), $\mathrm{NgR}_{9}$ (salmon red) and $\mathrm{NgR}_{13}$ (khaki) were isolated.

Carotenoid pigments. The visible spectra of 15 distinct pigments were obtained, and the spectral and chromatographic properties are summarized in Table 1.

$\beta$-Carotene, a pigment widely distributed in bacteria, was not formed by $M$. aurum. The 
Table 2. Distribution of the carotenes in M. aurum strain $A^{+}$and its mutants

\begin{tabular}{|c|c|c|c|c|c|c|c|}
\hline \multirow[b]{2}{*}{ Pigment } & \multicolumn{7}{|c|}{ Percentage of pigment in strain } \\
\hline & $\mathrm{A}^{+}$ & $\mathbf{A}_{8}$ & $\mathrm{~A}_{13}$ & $\mathrm{NgR}_{5}$ & $\mathrm{NgR}_{8}$ & $\mathrm{NgR}_{\mathrm{g}}$ & $\mathrm{NgR}_{13}$ \\
\hline I & 13 & $\mathbf{0}$ & 4 & 19 & 0 & 10 & 9 \\
\hline II & 14 & $\mathbf{0}$ & 10 & $\mathbf{0}$ & $(+)$ & $\mathbf{0}$ & 0 \\
\hline III & $\mathbf{0}$ & 0 & $(+)$ & $\mathbf{0}$ & $(+)$ & 2 & $\mathbf{0}$ \\
\hline IV & 0 & $\mathbf{0}$ & 0 & 10 & 0 & 0 & $\mathbf{0}$ \\
\hline V & $\mathbf{0}$ & 0 & $(+)$ & $\mathbf{0}$ & $\mathbf{0}$ & $\mathbf{0}$ & 60 \\
\hline VI & $\mathbf{0}$ & 0 & 0 & 17 & $\mathbf{0}$ & $\mathbf{0}$ & $\mathbf{0}$ \\
\hline VII & $\mathbf{0}$ & 0 & 0 & 19 & 46 & $\mathbf{0}$ & 0 \\
\hline VIII & $\mathbf{0}$ & 29 & $\mathbf{0}$ & $\mathbf{0}$ & 0 & $(+)$ & 0 \\
\hline IX & $(+)$ & $\mathbf{0}$ & 22 & 6 & $\mathbf{0}$ & 58 & 30 \\
\hline $\mathrm{X}$ & 0 & $\mathbf{0}$ & $\mathbf{0}$ & $\mathbf{0}$ & $\mathbf{0}$ & 22 & 0 \\
\hline XI & 45 & 0 & 26 & $\mathbf{0}$ & $\mathbf{0}$ & $\mathbf{0}$ & $\mathbf{0}$ \\
\hline XII & 8 & $\mathbf{0}$ & 6 & 0 & $(++)$ & 0 & 0 \\
\hline XIII & 0 & o & 0 & 0 & 0 & 0 & 4 \\
\hline XIV & 9 & 40 & $(+)$ & 0 & $(++)$ & $(+)$ & 0 \\
\hline $\mathrm{XV}$ & 0 & 30 & 0 & 0 & 0 & 0 & 0 \\
\hline
\end{tabular}

$(+)$, Pigment present in trace amounts; 0 , not detected; $(++)$, the percentage of the pigment was not estimated satisfactorily, but pigments XII and XIV represented about $50 \%$ of the epiphasic fraction of strain $\mathrm{NgR}_{\mathbf{8}}$.

Table 3. Distribution of epiphasic pigments in the extracts of $M$. aurum strain $\mathrm{A}^{+}$and its mutants

\begin{tabular}{ll} 
Strain & \multicolumn{1}{c}{$\begin{array}{c}\text { Epiphasic } \\
\text { pigments* (\%) }\end{array}$} \\
$\mathrm{A}_{13}$ & $36,40,58$ \\
$\mathrm{NgR}_{13}$ & 59,96 \\
$\mathrm{NgR}_{8}$ & 48,92 \\
$\mathrm{NgR}_{12}$ & 94 \\
$\mathrm{NgR}_{5}$ & 74,96 \\
$\mathrm{NgR}_{9}$ & 56,98 \\
$\mathrm{~A}_{8}$ & $21,44,58,68$ \\
$\mathrm{~A}_{11}$ & 20 \\
$\mathrm{~A}^{+}$ & 47
\end{tabular}

* The different values represent results from different experiments.

major pigment formed was pigment XI which was tentatively identified as leprotene on the basis of its retention on t.l.c. ( $R_{F}=0.52$ as opposed to $R_{F}=0.80$ for $\beta$-carotene) and by the characteristic shift in its spectrum in benzene [maxima in hexane, (425 to 430 ), 450 and $480 \mathrm{~nm}$; maxima in benzene, (435 to 440$), 460$ and $487.5 \mathrm{~nm}$ ].

The absorption spectrum of pigment VII was indistinguishable from that of $\gamma$-carotene, the known immediate precursor of $\beta$-carotene. However, because these bacteria form the bicyclic aromatic leprotene instead of $\beta$-carotene, we think that the pigment VII may not be $\gamma$-carotene. The spectrum of pigment III was identical to the spectrum of pigment I (neurosporene). Pigment III moved less rapidly on t.l.c. plates than neurosporene and was tentatively identified as a dihydroxy derivative of the latter. In addition to lycopene (pigment IX), these bacteria formed two other lycopene-like pigments (pigments IV and VI) differing in their chromatographic properties.

Distribution of the pigments. The distribution of the carotenoid pigments in the tacterial strains is shown in Table 2. The major carotenes in strain $\mathrm{A}^{+}$were pigments $\mathrm{XI}(45 \%)$, II $(14 \%)$ and $I(13 \%)$; in strain $A_{13}$, which formed the same pigments in larger quantities, 

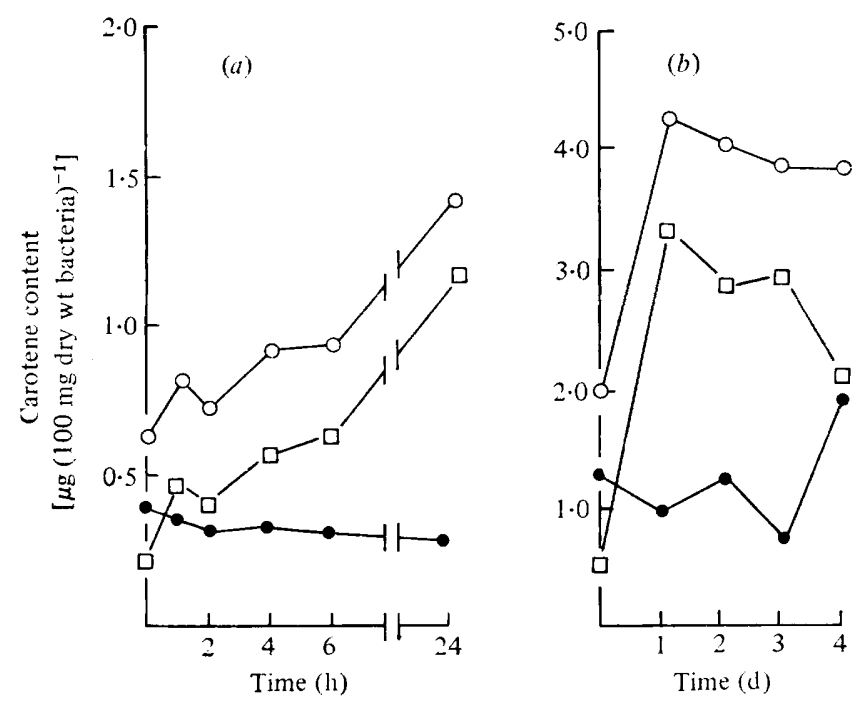

Fig. 2. Biosynthesis of carotenoid pigments. Bacteria were grown in nutrient broth containing $10^{-4} \mathrm{M}$-diphenylamine, then harvested, washed, resuspended in fresh medium and incubated in a shaking water bath at $37^{\circ} \mathrm{C}$. Samples were removed at the indicated times and the amount of carotenoid was estimated. $(a)$ and $(b)$ represent different experiments. $\bigcirc$, Total carotenoids; $\square$, epiphasic pigments; $\bigcirc$, hypophasic pigments.

the distribution was XI (26\%), II (10\%) and IX (22\%). Strain $\mathrm{A}_{8}$ did not form any of the usual carotenes and accumulated three unknown yellow pigments (VIII, XIV and XV).

The major pigment accumulated by strain $\mathrm{NgR}_{\mathbf{8}}$ was pigment VII (chlorobactene?), while strain $\mathrm{NgR}_{5}$ accumulated pigments I (19\%), VII (19\%) and VI (17\%). Pigments II and XI, the suspected end-products of carotene synthesis in $M$. aurum, were not found in the extracts of these mutants. Strains $\mathrm{NgR}_{9}$ and $\mathrm{NgR}_{\mathbf{1 3}}$ differed in that the former accumulated pigments IX (58\%), I $(10 \%)$ and X (about $22 \%$ ), while the latter accumulated IX $(30 \%)$ and large amounts $(60 \%)$ of an unknown pigment, V. Pigment VII (19\%) was found in extracts of strain $\mathrm{NgR}_{5}$ but not in extracts of strain $\mathrm{NgR}_{13}$.

All strains formed xanthophylls. The proportion of epiphasic pigments varied between strains and between experiments (Table 3). The factors that may affect the amount of carotenoids that accumulate, such as the growth conditions or the age of the culture, were not investigated.

During the preparation of the pigments, particularly from strain $\mathrm{NgR}_{9}$, the acetoneinsoluble lipids contained a red precipitate. Extensive extraction with methanol did not solubilize this material, which was dissolved with the neutral lipids in chloroform. The red chloroform solution gave a spectrum identical with that of lycopene and when applied on t.l.c. plates it co-chromatographed with pigment IX (lycopene). Presumably, therefore, the red precipitate was lycopene that coprecipitated with the acetone-insoluble lipids.

Time course of carotenogenesis. When DPA-treated cells were harvested, resuspended in fresh medium and incubated without forced aeration, there was no accumulation of newly formed carotenoids. Forced aeration, either by incubation in a shaker water bath at 100 strokes $\mathrm{min}^{-1}$ or in flasks containing magnetic stirrers, was required to obtain carotenogenesis. The time course of carotenogenesis (Fig. $2 a$ ) indicated that synthesis of the carotenoid pigments started within $1 \mathrm{~h}$ after removal of DPA. The spectrum of the total epiphasic pigments changed progressively after the removal of the inhibitor. The absorption maxima of the major end-product, pigment XI, were already detectable $2 \mathrm{~h}$ after removal of 
DPA, and the concentration of this pigment increased with time. The time of appearance of the hypophasic pigments varied widely from experiment to experiment, but was always late (Fig. 2b). These results are consistent with the conclusion that the epiphasic pigments were rapidly and sequentially formed. The late appearance of the hypophasic pigments made it difficult to decide whether they were formed by ancillary non-enzymic degradative reactions.

$\zeta$-Carotene, which was not found in the extracts of strain $\mathrm{A}^{+}$and the various mutants, was isolated from the bacteria after the removal of DPA.

\section{DISCUSSION}

This investigation confirms the report that MNNG is an efficient mutagen in the mycobacteria (Konickova-Radochova \& Malek, 1969) and supports the contention that mutants carrying genetic blocks affecting specific reactions in carotenoid synthesis might be useful tools in the investigation of these pigments throughout the genus Mycobacterium.

From the chemotaxonomic point of view, this study revealed that $M$. aurum is not capable of forming $\beta$-carotene. Instead it formed pigment XI, which we tentatively identified as leprotene. The immediate precursor of pigment XI was probably pigment VII. This pigment had spectral and chromatographic properties identical to $\gamma$-carotene; however comparison of the known structures of $\beta$-carotene, $\gamma$-carotene, leprotene and chlorobactene (Liaaen-Jensen et al., 1964; Liaaen-Jensen, 1965) lead us to suspect that it might be chlorobactene.

The xanthophylls in $M$. aurum did not derive from the final end-products but seemed to be formed from an earlier branch-point, the exact location of which has not yet been established. On the other hand, because hypophasic pigments were found in the extracts of all the mutant strains, and appeared late in DPA-inhibition experiments, it is also possible that they were the products of ancillary non-enzymic reactions of the carotenes that accumulated in cultures maintained in the incubator for more than $8 \mathrm{~d}$ (the average generation time $M$. aurum is $8 \mathrm{~h}$ ). To resolve this question we are searching for mutants that do not form hypophasic pigments.

The isolation of strain $\mathrm{A}_{13}$ which differed from the parental strain $\mathrm{A}^{+}$only in the amount and not in the nature of the pigments formed may indicate that the synthesis of these pigments is subject to regulation.

$\zeta$-Carotene, the known precursor of neurosporene, was not found in extracts of strain $\mathrm{A}^{+}$or any of its mutants. Furthermore, our efforts to obtain a mutant that accumulated $\zeta$-carotene have been unsuccessful. It is possible that the conversion of $\zeta$-carotene into neurosporene occurred very rapidly in these strains making it difficult to isolate this compound in satisfactory amounts for analysis, and the failure to isolate mutants that accumulated it may signify that the early conversions from phytoene to neurosporene were catalysed by the same enzyme, as suggested by Liaaen-Jensen et al. (1961).

This work was submitted by V. Levy-Frebault in partial fulfilment of the requirements of a Diplome d'Etudes Approfondies in Microbiology, University of Paris VII.

\section{REFERENCES}

Batra, P. P. (1971). Mechanisms of light induced carotenoid synthesis in nonphotosynthetic plants. Photophysiology 6, 47-76.

DAVID, H. L. $(1974 a)$. Biogenesis of $\beta$-carotene in Mycobacterium kansasii. Journal of Bacteriology 119, 527-533.

DAvid, H. L. (1974b). Carotenoid pigments of Mycobacterium kansasii. Applied Microbiology 28, 696-699.

Davies, B. H. (1965). Analysis of carotenoid pig- ments. In Chemistry and Biochemistry of Plant Pigments, pp. 489-532. Edited by T. W. Goodwin. London: Academic Press.

Ebina, T., Mokomyia, M., Munakata, K. \& Satake, O. (1962). Pigments of unclassified mycobacteria. American Review of Respiratory Disease 86, 740-743.

GoodwIN, T. W. (1954). Carotenoids: Their Comparative Biochemistry. New York: Chemical Publishing Co. 
Griffiths, M. \& Stanier, R. Y. (1956). Some mutational changes in the photosynthetic pigment system of Rhodopseudomonas spheroides. Journal of General Microbiology 14, 698-715.

HertzberG, S. \& LiaAen-Jensen, S. (1967). XX. The carotenoids of Mycobacterium phlei strain Vera. 2. The structures of the phlei-xanthophylls two novel tertiary glucosides. Acta chemica scandinavica 20, 15-41.

Howes, C. D. \& BAtra, P. P. (1970). Accumulation of lycopene and inhibition of cyclic carotenoids in the presence of nicotine. Biochimica et biophysica acta 222, 174-179.

KoníčKová-Radochová, M. \& MáleK, I. (1969). The mutagenic effect of nitrosoguanidine in Mycobacterium phlei PA. Folia microbiologica 14, 201-207.

LIAAEN-JENSEN, S. (1965). XVIII. Aryl carotenes from Phaeobium. Acta chemica scandinavica 19, 1025-1030.

LIAAEN-JENSEN, S. \& JeNSEN, A. (1971). Quantitative determination of carotenoids in photosynthetic tissues. Methods in Enzymology 23, 596.

LiaAen-Jensen, S., Cohen-Bazire, G. \& Stanier, R. Y. (1961). Biosynthesis of carotenoids in purple bacteria: a re-evaluation based on considerations of chemical structure. Nature, London 192, 11681171.

LiaAen-Jensen, S., Hegge, E. \& Jackman, L. M. (1964). XVIJ. The carotenoids of photosynthetic green bacteria. Acta chemica scandinavica 18, 1703-1718.

Runyon, E. (1959). Anonymous mycobacteria in pulmonary disease. Medical Clinics of North America 43, 273-290.

TsukamurA, M. (1966). Adansonian classification of mycobacteria. Journal of General Microbiology 45, 253-273.

Turian, G. (1950). Recherches sur la synthèse des caroténoides chez un bacille paratuberculeux. III. Inhibition de la pigmentation par la diphenylamine. Helvetica chimica acta 33, 1988-1993. 